\title{
Evaluation of Anticlastogenic effects of Glycyrrhiza gabra root extract against Cyclophosphamideinduced Chromosomal aberration in Swiss albino Mice
}

\author{
Varsha Sharma, R. C. Agrawal \\ Dept. of Research Priyamvada Birla Cancer Research Institute, Satna, India.
}

\begin{tabular}{l} 
ARTICLE INFO \\
\hline Article history: \\
Received on: 05/04/2015 \\
Revised on: 11/05/2015 \\
Accepted on: 24/05/2015 \\
Available online: 27/06/2015 \\
\hline Key words: \\
Bone marrow; Chromosomal \\
aberration; Clastogenic; \\
Cyclophosphamide; \\
Glycyrrhiza glabra; Immuno- \\
enhancing; Swiss albino.
\end{tabular}

\begin{abstract}
Background: Indian subcontinent is a vast repository of medicinal plants that are used in traditional medical treatments. Various indigenous systems such as Siddha, Ayurveda, Unani and Allopathy use several plant species to treat different ailments. Ayurveda includes diet and herbal remedies, while emphasizing the body, mind and spirit in disease prevention and treatment. Since origin of human's life, medicinal plants continue to play a curative and therapeutic role in preserving human health against disease. Herbal plants have been a rich source of medicines because they produce a host of bioactive molecules, most of which probably evolved as chemical defenses against predation or infection.

Objective: The study was aimed towards evaluation of Immuno-enhancing potential of hydromethanolic root extract of Glycyrrhiza glabra through the prevention of Mutagenecity caused by Clastogenic or Chemotherapeutic agents in bone marrow cells of Swiss albino mice.

Methods: For the assessment of Anti-clastogenic efficacy of G. glabra hydromethanolic root extract, the Bone marrow Chromosomal aberration assay was used and the single i.p. of G. glabra extract given at the doses of 300,450 and $600 \mathrm{mg} / \mathrm{kg}$ body weight, 24 hours prior the administration of Cyclophosphamide at the dose of 50 $\mathrm{mg} / \mathrm{kg}$ body wt.

Results: The present investigation revealed that, the doses of 450 and $600 \mathrm{mg} / \mathrm{kg}$ body wt. provided significant protection against Cyclophosphamide induced Chromosomal aberration in the bone marrow cells of Swiss albino mice. A dose dependent inhibition was observed which was statistically significant $(\mathrm{p}<0.05)$ when compared to Cyclophosphamide group. It was observed that G. glabra root extract alone has not induced any Chromosomal aberration.

Conclusion: Thus in Mutagenecity assay, G. glabra root extract possess protective potential against Cyclophosphamide induced Mutagenecity in mouse Bone marrow cells. It may be concluded that this herbal extract have Anti-clastogenic agents which showed Anti-mutagenic nature.
\end{abstract}

\section{INTRODUCTION}

Plant derived drugs came into use in the modern medicine through the uses of plant material as indigenous cure in folklore or traditional systems of medicine. Plants have been a rich source of medicines because they produce a host of bioactive molecules, most of which probably evolved as chemical defenses against predation or infection (Cox \& Balick, 1994). Indian subcontinent is a vast repository of medicinal plants that are used in traditional medical treatments (Chopra et al., 1956), which also forms a rich source of knowledge.

* Corresponding Author

Varsha sharma, Dept. of Research Priyamvada Birla Cancer Research

Institute, Satna, India. Email:varshas81@gmail.com
Herbs and spices constitute are the most important part of human diet. In addition to flavor, they are famous for their nutritive, medicinal and preservative values (Dwivedi et al., 2014). The pharmacological treatment of disease began long ago with the use of herbs (Schulz et al., 2001). The various indigenous systems such as Siddha, Ayurveda, Unani and Allopathy use several plant species to treat different ailments (Rabe and Staden, 1997). Large numbers of plant species are a great source of biologically active compounds whose effect on human health or genetic. In recent years there has been greater interest in investigating compounds originating from plants and their effects on DNA. This is done with many different types of assays employing different organisms. The actions of these compounds may be involved in maintaining the balance between the consumption of mutagenic and antimutagenic 
substances, thus contributing to increases or reductions in the incidence of cancer in the population (Horn \& Vargas, 2003). Glycyrrhiza glabra Linn (Licorice/Mulaithi, Family; Fabaceae) is well known and an old age medicinal plant used in traditional medicine across the globe for its ethano-pharmacological value to cure varieties of ailments from simple cough to hepatitis (Sharma \& Agrawal, 2013). Glycyrrhiza glabra (Mulaithi) has been extensively used in Ayurveda, Unani and Homoeopathic medicine and has become a cynosure of modern medicine. Glycyrrhiza glabra is an herbaceous perennial, growing to $1 \mathrm{~m}$ in height, with pinnate leaves, grows in subtropical climates in rich soil. Below ground, the licorice plant has an extensive root system with a main taproot and numerous runners. A numbers of traditional healers have claimed the efficacy of Glycyrrhiza species for a variety of pathological conditions such as diuretic, choleretic, used as insecticide and indicated in traditional medicine for coughs, colds and painful swellings (Chopra et al., 2002) The yellow color of licorice is due to the flavonoid content of the plant, which includes liquiritin, isoliquiritin (a chalcone), and other compounds (Yamamura et al., 1992). Glycyrrhiza glabra Linn used as a mild laxative, anti-arthritic, anti-inflammatory, anti-biotic, anti-viral, anti-ulcer, anti-tussive, anti-oxidant, estrogenic, anti-diuretic, hypolipidmic agent. It is reported to contain important phytoconstituents such as glycyrrhizin, glycyrrhizinic acid, glabrin $\mathrm{A} \& \mathrm{~B}$, triterpene sterols, saponin, and isoflavons (Sharma \& Agrawal, 2013). A process by which the genetic information of an organism is changed in a stable manner, resulting in a mutation is known as mutagenesis or mutagenecity and a substance which causes mutation is called mutagen or clastogen or genotoxic agent. The chromosomes represent genetic material of an organism and are the most stable organic compound that maintains constancy both in number and structure. However chromosomes undergo unusual changes called as aberrations which can numerical or structural. Chromosomal aberrations (CA) are one of the important biological consequences of human exposure to ionizing radiation and other genotoxic agents. In epidemiological studies, it has been shown that people with elevated frequencies of Chromosomal aberration in their peripheral blood lymphocytes have a significantly elevated risk of developing cancer. Many types of cancers are associated with specific types of Chromosomal aberration which are etiologic for the cancer in question (Obe et $a l .$, 2002). Structural chromosome aberrations may be induced via DNA breaks by various types of mutagens. The purpose of this study was to determine the protective effects of Glycyrrhiza glabra hydromethanolic root extract through the stimulation in immune responses against clastogenesis/mutagenesis/genotoxicity which was induced by Cyclophosphamide using short term assay in bone marrow cells of Swiss albino mice.

\section{MATERIAL \& METHOD}

\section{Plant Collection and Identification}

The Root of Glycyrrhiza glabra were procured from Bhopal (Madhya Pradesh), India and authenticated by Botanist,
Dr. Zia Ul Hasan (Voucher Specimen No: 441/BOT/Safia/13) Prof. \& Head, Dept. of Botany, Safia Science College, Bhopal, Madhya Pradesh (India).

\section{Chemicals}

Cyclophosphamide was purchased from Sigma chemical Co., U.S.A. Other chemicals were reagent grade and purchased locally.

\section{Preparation of Glycyrrhiza glabra Root Extract}

The collected root were dried in shade and grinded with mechanical grinder. About $30 \mathrm{~g}$ powder was filled in separating funnel with $50 \%$ methanol for $48 \mathrm{hrs}$. The collected residues kept at $55-60^{\circ} \mathrm{C}$ in Boiling Water Bath to concentrate it and finally transfer into the Hot Air Oven to dry it. About 5.8gm powder of crude extract was obtained (Yield $=19 \%$ ) and used for the further studies.

\section{Experimental Animals}

Random bred of male Swiss albino mice (7- 8 weeks old), weighing $23 \pm 2$ gm body wt. obtained from the animal colony of our Research Centre were used for the experiments. Experimental animals were approved by Institutional Legislation, regulated by the Committee for the purpose of Control and Supervision of Experiments on Animals (CPCSEA), Ministry of Social Justice and Empowerment, Government of India. The Project No. is 1695/PO/C/13/CPCSEA/2. These animals were housed in polypropylene cages in the animal house at temperatures of $22 \pm 1.5^{\circ} \mathrm{C}$ and 12 hours light and dark cycle. The animals were provided with standard pallet diet (from Golden feed, New Delhi, India) and water ad libitum.

\section{Anticlastogenic activity \\ Chromosomal aberration Assay}

Chromosomal aberration assay was performed as per the method reported by Preston et al., 1987 and as standardized by Agrawal \& Kumar, 1999. The animals were divided in to six different groups in which each group contain 4 animals. The requisite dose of crude extract was dissolved in appropriate solvent and administrated as single i.p. dose per mouse before $24 \mathrm{hrs}$ of Cyclophosphomide (CP) administration to the animals of each group. Positive Control group received Cyclophosphamide in $0.9 \%$ saline. The G. glabra root extract was prepared in stock as per the $\mathrm{LD}_{50}$ observed. The extract was administered in 3 different doses. The experimental groups were as follows:

\section{Experimental Groups}

Group I (Positive control): Single i.p. of CP (50mg/kg bwt) administered.

Group II (G. glabra extract + CP): $300 \mathrm{mg} / \mathrm{kg}$ bwt of Glycyrrhiza glabra hydromethanolic root extract before $24 \mathrm{hrs}$ of Cyclophosphamide $50 \mathrm{mg} / \mathrm{kg}$ bwt.

Group III (G. glabra extract + CP): $450 \mathrm{mg} / \mathrm{kg}$ bwt of Glycyrrhiza glabra hydromethanolic root extract before $24 \mathrm{hrs}$ of Cyclophosphamide $50 \mathrm{mg} / \mathrm{kg}$ bwt. 
Group IV (G. glabra extract + CP): $600 \mathrm{mg} / \mathrm{kg}$ bwt of Glycyrrhiza glabra hydromethanolic root extract before $24 \mathrm{hrs}$ of Cyclophosphamide $50 \mathrm{mg} / \mathrm{kg}$ bwt.

Group V (G. glabra extract alone): Single i.p. of $300 \mathrm{mg} / \mathrm{kg}$ bwt of Glycyrrhiza glabra hydromethanolic root extract.

Group VI (Vehicle alone): Double distilled water (DDW).

Colchicine $(25 \mathrm{mg} / \mathrm{kg}$ body wt.) was administered intra-peritoneally in each group, before 2 hours of harvesting the cells. After that animals were sacrificed by cervical dislocation and slides of bone marrow were prepared. A total of 100 well spread metaphase plates were scored for chromosomal aberrations at a magnification of $1000 \times(100 \times 10)$ for each group.

\section{Study Parameters}

Different types of Chromosomal aberrations such as Chromosomal breaks, Gaps, Rings, Fragments, Centromeric association, were scored and expressed as \% chromosomal aberrations.

\section{Statistical Analysis}

The experimental results were expressed as Mean \pm SEM. Data were assessed followed by Student's ' $t$ ' test. Whereas, $p<0.05$ value was considered as statistically significant.

\section{RESULTS}

The results indicated that, when the Cyclophosphamide was given at a single dose i.e. $50 \mathrm{mg} / \mathrm{kg}$ body weight cause a high incidence of Chromosomal aberration in bone marrow cells of Swiss albino mice. However, the single administration of Glycyrrhiza glabra hydro-methanolic root extract at the doses of $300,450,600 \mathrm{mg} / \mathrm{kg}$ body $\mathrm{wt}, 24 \mathrm{hrs}$ prior to the single administration of Cyclophosphamide at the dose of $50 \mathrm{mg} / \mathrm{kg}$ body wt. provided significant protection against $\mathrm{CP}$ induced Chromosomal aberration in bone marrow cells of mice. The percentage of incidence of Chromosomal aberration in Cyclophosphamide alone group i.e. Positive control, was observed as $71.67 \pm 4.34$. The Group III $(450 \mathrm{mg} / \mathrm{kg}$ bwt + CP $50 \mathrm{mg} / \mathrm{kg}$ bwt $)$ and IV $(600 \mathrm{mg} / \mathrm{kg}$ bwt + CP $50 \mathrm{mg} / \mathrm{kg}$ bwt) provided significant protection when compared with the Cyclophosphamide alone treated group in the student ' $\mathrm{t}$ ' test $(\mathrm{p}<0.05)$. The protection percentage of Glycyrrhiza glabra root extract at the doses of 300 , $450,600 \mathrm{mg} / \mathrm{kg}$ body wt. along with Cyclophosphamide were found to be $26.52 \%, 39.53 \%$ and $46.98 \%$ respectively. Chromatid breaks and fragmentation types of Chromosomal aberrations were found to be significantly reduced by Glycyrrhiza glabra root extract in dose dependent manner. However, the other types of aberration such as Chromosomal gaps, Centromeric associations and Ring formation have not shown any protection. The results suggested that, the Glycyrrhiza glabra root extract showed anti-mutagenic activity. Results are summarized and represented in a Graphical view Graph I-VII.

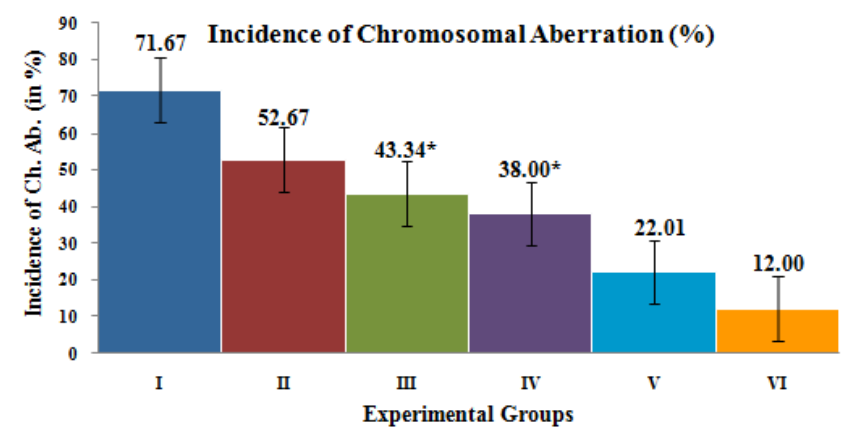

Graph. (I): Showing effect of G. glabra root extract on \% incidence of Chromosomal Aberration

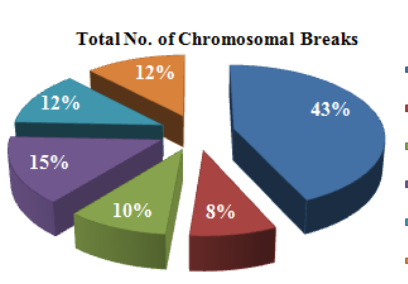

Graph (II): Showing Chromosomal breaks in different groups.

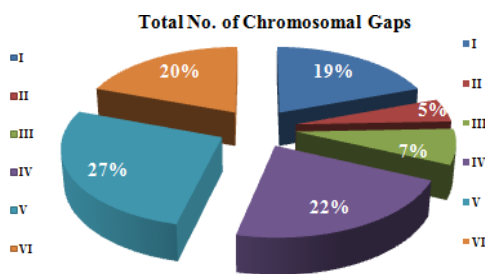

Graph. (III): Showing Chromosomal gaps in Gaps in different groups.

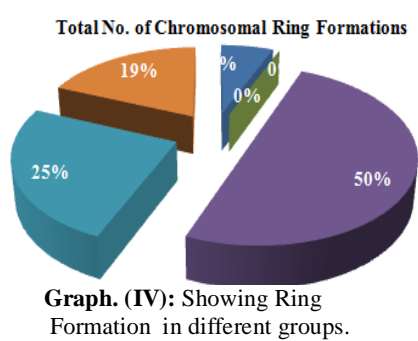

Formation in different groups.

Total No. of Centromeric Associations

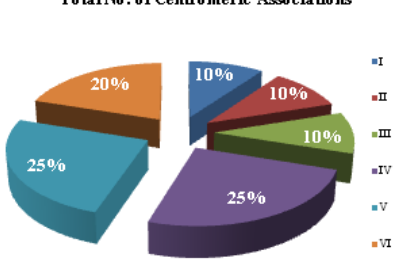

Graph (VI): Showing Centromeric Associations in different groups.

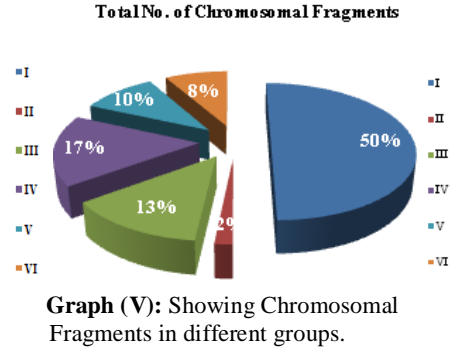
Graph (V): Showing Chromosom
Fragments in different groups.

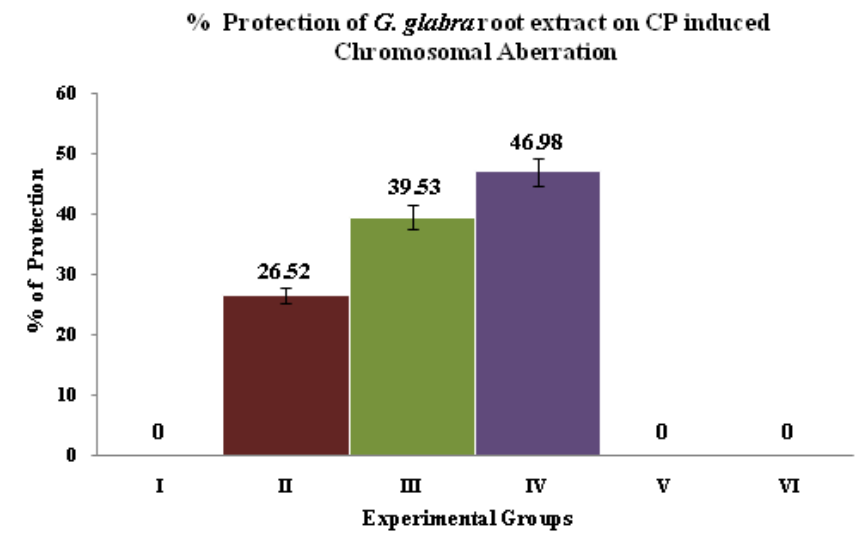

Graph (VII): Showing Protection \% of G. glabra root extract on CP induced Chromosomal Aberration in mice. 


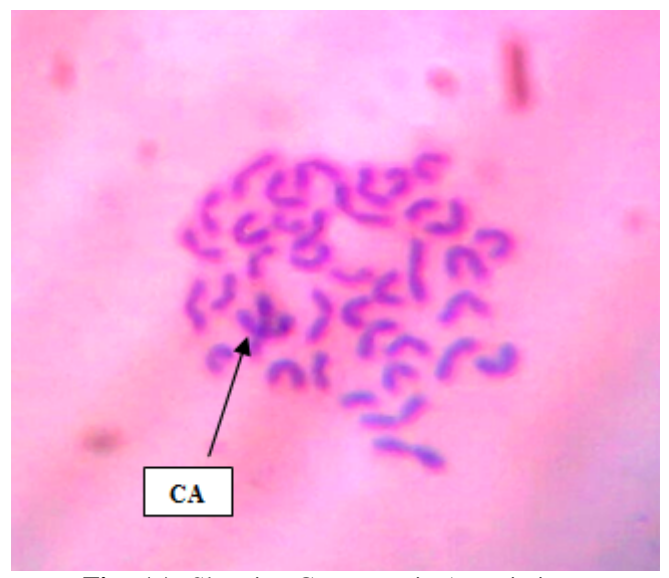

Fig. (a): Showing Centromeric Association.

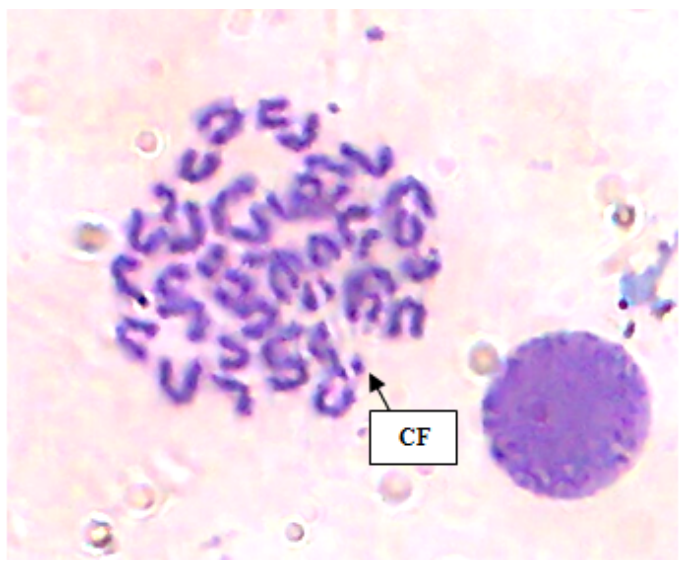

Fig. (b): Showing Chromosomal Fragments.

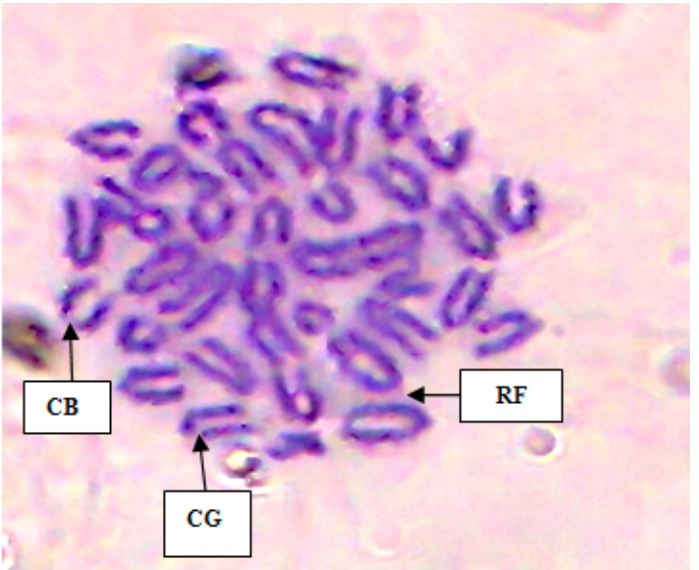

Fig. (c): Showing Chromosomal Breaks, Chromosomal Gaps and Ring Formation.

\section{DISCUSSION}

Mutagenecity is the biomarker of cancer. Cancer and other chronic diseases share some common pathogenic mechanisms, such as DNA damage, oxidative stress, and chronic inflammation. These diseases can be controlled by forestalling the exposure to well-acknowledged risk factors and to render the organism more resistant to mutagens/carcinogens and/or to inhibit progression of the disease by administering chemopreventive agents (Gowri \& Chinnaswamy, 2011). Chemotherapy and surgery are standard methods for treatment of these diseases, although not been fully effective. Most of the anti-tumor drugs currently used in chemotherapy are toxic to normal cells and cause toxicity for immune cells (Azadmehr et al., 2011). For example Cyclophosphamide (CP) belong a class of drugs known as alkylating agent, which have been used to treat some kind of cancer. After studying the mode of action of $\mathrm{CP}$, it demonstrated that, this induces inhibition of DNA replication and leading cell death. CP exerts its cytotoxic effects on both resting and dividing lymphocytes. In that case it is working as immunosuppressant. It is a potent anticancer drug but it also affects normal cell division by decreasing the immune responses. The formation of Chromosomal aberration with $\mathrm{CP}$ administration showed that it has mutagenic behavior. Therefore, the identification of new anti-cancer drug with low or no side effects even stimulating effects on immune system has become an essential goal in many studies of immunopharmacology. Natural antimutagens from edible and medicinal plants are of particular importance because they may be useful for human cancer prevention and have no undesirable xenobiotic effects on living organisms. Natural antioxidants may reduce or inhibit the mutagenic potential of mutagens and carcinogens. The cellular mutability controlled by natural antimutagens can provide ways for preventing mutations that conceivably results in cancer as well as diseases caused by genotoxic agents (Zahin et al., 2010). Mutagenic and antimutagenic activities have been correlated with the presence of certain phytochemical substances.

In the present investigation the hydromethanolic root extract of $G$. glabra exhibited anticlastogenic/antigenotoxic potential by decreasing the Chromosomal abnormalities at the given doses. It may be due to the reducing immunosuppressant effects of $\mathrm{CP}$ and increasing the immune responses in the experimental animals. The significant antimutagenic activity in the above three different doses of G. glabra extract against direct acting clastogens/mutagens suggest that this extract may directly protect DNA damage from mutagens.

Natural substances such as flavonoids and tannins or their derivatives, present in herbs and spices, were previously described as possessing antimutagenic properties and these metabolites could be involved in mutagen deactivation (Horn \& Vargas, 2003). Recent research has confirmed that plant flavonoids inhibit the mutagencity induced by chemical mutagens (Miyazawa \& Hisama, 2003) Flavonoids are consumed naturally through the intake of beverages such as beer, coffee and wine (on average $\sim 1 \mathrm{mg} / \mathrm{l}$ flavonoids) and may reach $25 \mathrm{mg} / \mathrm{l}$ in black tea (Hertog et al., 1993). According to MacGregor \& Jurd, 1978, these are relatively stable compounds, resistant to heat, light and oxygen, and are moderately acidic. Mainly antimutagenic activity has also been attributed due to tannins. These are phenolic compounds and are widely distributed in plants (Horn \& Vargas, 2003). Studies in cell cultures performed by Imanishi et al., 1991, revealed that tannins have an antimutagenic effect. One of the investigations demonstrated the presence of phytotherueptic molecules such as; Flavonoids, Tannins, Glycosides, triterpenoid, 
saponins etc. in the hydromethanolic crude extract of G. glabra. This investigation also revealed that the extract have antibacterial and in vitro antioxidant potential (Sharma et al., 2013). Another set of experiment showed the in vivo antioxidant \& hepatoprotective potential of G. glabra hydromethanolic root extract (Sharma \& Agrawal, 2014). Several natural compounds and antioxidant agents, such as Vanillin, Garlic acid, Humic acid, Fatty acids, Squalene and Tochu have shown antimutagenic properties against chromosomal damage in mice (Raja et al., 2011). Similar type of study was also done using some other herbal compound such as T. chebula (Raja et al., 2011), S. lycopersicum (Raja et al., 2010), B. variegata (Pandey \& Agrawal, 2010). The effects of Glycyrrhiza glabra L. extract, glycyrrhizinic acid, 18 alpha- and 18 beta-glycyrrhetinic acids on the mutagenicity of the ethyl methanesulfonate, N-methyl-N'-nitro-Nnitrosoguanidine, and ribose-lysine Maillard model systems were investigated by using the Salmonella/microsome reversion assay. Glycyrrhiza glabra extract exhibited antimutagenic activity against ribose-lysine. (Zani et al., 1993). A recent investigation was conducted for the study of antimutagenic effects of G. glabra hydromethanolic root extract using Micronucleus assay in mice model. The chemically induced Micronucleus formation was found to be significantly suppressed which showed this extract has the ability to fight with the clastogenic/ genotoxic agents (Sharma et al., 2014).

\section{CONCLUSION}

On the basis of this study, it may concluded that $G$. glabra root extract (hydromethanolic) have shown significant protection against Cyclophosphamide induced Chromosomal aberration in Bone marrow cells of animals. The presence of Flavonoids, Tannins, Glycosides, Saponins, Terpenoids, Alkaloids etc. enhance medicinal properties of Glycyrrhiza glabra Linn. From the above findings it seems that, the hydromethanolic crude extract of G. glabra possesses anti-mutagenic potential. The antimutagenic activity of the extract was found to be dose dependent. It may also conclude that, the Anticlastogenic/Antimutagenic effect of extract was due to presence of hydrolysable flavonoids and tannins. Further studies are however needed to isolate and characterize the active principles responsible for anti-mutagenic activity. After that, this herbal formulation may be utilized to formulate anti-mutagenic drugs and in future it may be used as an alternative drug for cancer because most of the anticancer drugs used in present days showed mutagenic responses in animal models or may be include with the chemotherapy because it may able to reduce the side effects of chemotherapeutic agents and increase the life span of patients who are suffering from cancer.

\section{ACKNOWLEDGEMENTS}

The authors are thankful to Dr. S. K. Maheshwari, Medical Director of M. P. Birla Hospital, Satna, for providing lab facilities to carry out above work.

\section{REFERENCES}

Agrawal RC, Kumar S. Prevention of Cyclophosphomide induced chromosomal aberration in bone marrow cells of mice by indole3-carbinol. Food \& chemical toxicology, 1999; 10(6): 137-141.

Azadmehr A, Hajiaghaee R, Afshari A, Amirghofran Z, Refieian-Kopaei M, Yousofi-Darani H, Shirzad H. Evaluation of in vivo immune response activity and in vitro anti-cancer effect by Scrophularia megalantha. J Med Plants Res, 2011; 21: 2365-2368.

Chopra RN, Nayar SL, Chopra IC. 1956. In Glossary of Indian medicinal plants, Council of Scientific and Industrial Research, New Delhi, 1: 197.

Chopra RN, Nayar SL, Chopra IC. 2002. Glossary of Indian Medicinal Plants. NISCAIR, CSIR, New Delhi.

Cox PA, Balick MJ. The ethno-botanical approach to drug discovery. Sci Am, 1994; 270(6): 82-87.

Dwivedi R, Sharma V, Agrawal RC, Bhargava S. Qualitative estimation of phytoconstituents and in vitro antioxidant potential of Tinospora cordifolia stem extract. Int J Bio Pharma Res, 2014; 5(2): 114 119.

Gowri S, Chinnaswamy P. Evaluation of in vitro antimutagenic activity of Caralluma adscendens Roxb in bacterial reverse mutation assay. J Nat Prod Plant Resour, 2011; 1(4): 27-34.

Hertog MGL, Hollman PCH, Van-Deputte B. Content of potentially anticarcinogenic flavonoids of tea infusions, wines and fruit juices. J Agric Food Chem, 1993; 41: 1242-1246.

Horn RC, Vargas VMF. Antimutagenic activity of extracts of natural substances in the Salmonella/microsome assay. Mutagenesis, 2003;18(2):113-118.

Imanishi H, Sasaki YF, Ohta T, Watanabe M, Kato T, Shirasu Y. Tea tannin components modify the induction of sister-chromatid exchanges and chromosome aberrations in mutagen-treated cultured mammalian cells and mice. Mutation Research, 1991; 259: 79-88.

MacGregor JT, Jurd L. Mutagenicity of plant flavonoids: structural requirements for mutagenic activity in Salmonella typhimurium. Mutation Research, 1978; 54: 297-309.

Miyazawa M, Hisama M. Antimutagenic activity of flavonoids from Chrysanthemum morifolium. Biosci Biotechnol Biochem, 2003; 67(10): 2091-2099.

Obe G, Pfeiffer P, Savage JRK, Johannes C, Goedecke W, Jeppesen P, Natarajan AT, Martinez-Lopez W, Folle GA, Drets ME. Chromosomal aberrations: formation, identification and distribution. Mutation Research, 2002; 504(1-2): 17-36.

Pandey S, Agrawal RC. Clastogenic analysis of Bauhinia variegata bark extract using micronucleus assay in mouse bone marrow cells. Am Eur J Toxicol Sci, 2010; 2(2): 112-114.

Preston RJ, Dean BJ, Galloway S, Holden H, Mcfee AF, Shelby $\mathrm{M}$. Mammalion in vivo cytogenetic assay- analysis of chromosomal aberrations in bone marrow cells. Mutation Research, 1987; 189: 157-165.

Rabe T, Staden JV. Antibacterial activity of South African plants used for medicinal purposes. J Ethnopharmacol, 1997; 56(1): 81-87.

Raja W, Agrawal RC, Ovais M. Effects of Solanum lycopersicum Fruit Extract on Cyclophosphamide-induced chromosome aberrations in mouse bone marrow cells. Pharmacologyonline, 2010; 1: 909-914.

Raja W, Pandey S, Agrawal RC. Studies on the Anticlastogenic Effect of Terminalia chebula Extract on Cyclophosphamide-Induced Micronucleus Formation and Chromosome Aberrations in Swiss albino Mice. Int J Gen, 2011; 1(2): 13-17, 2011.

Schulz V, Hansel R, Tyler VE. 2001. Rational Phytotherapy: A Physician's Guide to Herbal Medicine ( $4^{\text {th }}$ eds.), Springer-Verlag, Berlin.

Sharma V, Agrawal RC, Pandey S. Phytochemical screening and determination of anti-bacterial and anti-oxidant potential of Glycyrrhiza glabra root extracts. J Environ Res Develop, 2013; 7(4A): 1552-1558.

Sharma V, Agrawal RC, Shrivastava VK. Assessment of median lethal dose and antimutagenic effects of Glycyrrhiza glabra root 
extract against chemically induced micronucleus formation in Swiss albino mice. Int J Basic Clin Pharmacol, 2014; 3: 292-297.

Sharma V, Agrawal RC. Glycyrrhiza glabra: A plant for the future. Mint J Pharm Med Sci, 2013; 2(3): 15-20.

Sharma V, Agrawal RC. In vivo antioxidant and hepatoprotective potential of Glycyrrhiza glabra extract on carbon tetra chloride $\left(\mathrm{CCl}_{4}\right)$ induced oxidative-stress mediated hepatotoxicity. Int J Res Med Sci, 2014; 2: 314-320.

Yamamura Y, Kawakami J, Santa T, Kotaki H, Uchino K, Sawada Y, Tanaka N, Iga T. Pharmacokinetic profile of Glycerrhizin in healthy volunteers by a new high-performance liquid chromatographic method. J Pharm Sci, 1992; 81(10): 1042-1046.

Zahin M, Aqil F, Ahmad I. Broad spectrum antimutagenic activity of antioxidant active fraction of Punica granatum L. peel extracts. Mutat Res, 2010; 703(2): 99-107.
Zani F, Cuzzoni MT, Daglia M, Benvenuti S, Vampa G, Mazza P. 1993. Inhibition of mutagenicity in Salmonella typhimurium by Glycyrrhiza glabra extract, glycyrrhizinic acid, 18 alpha- and 18 betaglycyrrhetinic acids. Planta Med, 1993; 59(6):502-507.

\section{How to cite this article:}

Varsha Sharma, RC Agrawal. Evaluation of Anticlastogenic effects of Glycyrrhiza glabra root extract against Cyclophosphamide induced Chromosomal aberration in Swiss albino Mice. J App Pharm Sci, 2015; 5 (06): 127-132. 